\title{
Numerical Analysis on Reinforcement Range of a Closed Steel Sleeve against Collapse
}

\author{
Qing-Feng Yin $\mathbb{D}^{1,2}$ \\ ${ }^{1}$ China Construction Communications Construction Group Co. Ltd., Beijing 100142, China \\ ${ }^{2}$ School of Civil Engineering, Huaqiao University, Xiamen, Fujian 361021, China \\ Correspondence should be addressed to Qing-Feng Yin; 1106244363@qq.com
}

Received 28 January 2021; Revised 18 February 2021; Accepted 7 March 2021; Published 19 March 2021

Academic Editor: Faming Huang

Copyright (c) 2021 Qing-Feng Yin. This is an open access article distributed under the Creative Commons Attribution License, which permits unrestricted use, distribution, and reproduction in any medium, provided the original work is properly cited.

Before the shield machine begins to excavate, the end of the station structure often requires extensive soil reinforcement to ensure construction safety. Closed steel sleeve can prevent water leakage, sand leakage, and cave door collapse by balancing the water and soil pressure on the tunnel surface, thereby reducing the reinforcement range. In this study, a launching project of a closed steel sleeve is investigated; the Madis GTS finite element analysis software is used to simulate the triple-tube high-pressure jet-grouting pile to reinforce the water-rich sand layer. Soil displacement and stress after opening of the tunnel door are studied in detail at different longitudinal reinforcement lengths and transverse reinforcement scopes. The results show that, as the longitudinal reinforcement length increases, the displacement of the soil shows a decreasing trend, and the greater the length of the reinforced soil, the smaller the reduction in displacement. Furthermore, with the decrease of the lateral reinforcement range, though the soil settlement area has increased, the displacement remains unchanged. However, changing the end reinforcement range has no effect on the soil stress. In general, based on the strength and stability of the soil after the gate is cut out, the reinforcement range of the closed steel sleeve can be appropriately reduced compared to traditional reinforcement methods.

\section{Introduction}

Steel sleeve can form a confined space by injecting cement mortar to provide water and soil pressure on the face of the tunnel to prevent the risk of water leakage, sand leakage, and ground collapse, thereby reducing the end reinforcement range or even eliminating reinforcement requirement [1-4]. The high-pressure jet-grouting pile uses nozzles that extend into the underground soil to spray high-pressure cement slurry and mix it with the soil to form a columnar reinforcement. It has the advantages of simple construction and controllable grout injection range and is widely used in China and other countries [5-7].

Many scholars have conducted numerical simulation studies on the end reinforcement range. Hu et al. [8] numerically simulated the development and distribution of the temperature field on a large-diameter cup-shaped frozen soil wall and analyzed the influence of different factors on the temperature field. In addition to the physical reinforcement methods mentioned above, $\mathrm{Hu}$ et al. [9] also studied the initial reinforcement range of the shield when using chemical reinforcement (such as high-pressure jet grouting) and compared the soil deformation strength and surface settlement under different reinforcement ranges. Zhou et al. [10] introduced the process of grouting construction when the shield was started and received in detail and analyzed the stability of the excavation face of the shield under different horizontal and longitudinal reinforcement scopes using a numerical simulation method. Wu [11] performed a numerical simulation of the shield machine passing through a starting working well and compared the simulation data of the unreinforced end with the surface settlement value calculated according to the Peak formula. In terms of theoretical calculations, Luo et al. [12] studied the determination of the end soil reinforcement range and the establishment of a sand-soil composite stratum end sliding model and proposed a load equivalent model on the theory of soil strength and a sliding model of sandy soil according to the stability theory. Based on the slab strength theory, Lei et al. [13] simplified the mechanical model of simply 
supported rectangular slabs, divided the equivalent loads into uniformly distributed loads and triangular antisymmetric loads, and discussed the conditions of different reinforced soil thicknesses. Jiang and Jain [14] conducted end reinforcement effect statistics on a variety of layers and analyzed the relationship between longitudinal reinforcement length and shield diameter. It can be seen that the conventional numerical simulation and theoretical calculation of the end reinforcement range need to comprehensively analyze the strength, stability, and impermeability of the soil under the conditions of tunnel gate removal and end excavation. When the closed steel sleeve starts, the end reinforcement range only needs to ensure the strength and stability of the soil after the tunnel door is cut out. The end reinforcement range determined according to the existing research results is no longer applicable. Therefore, the reasonable range of end reinforcement at the beginning of the launch of the closed steel sleeve still needs further study.

In this study, through a closed steel sleeve project, the Madis GTS finite element analysis software is used to simulate the triple-tube high-pressure jet-grouting pile to strengthen the end soil. According to the survey report and drilling data, a three-dimensional numerical model is established, and the displacement and stress of the soil mass at different longitudinal reinforcement lengths and lateral reinforcement ranges after the gate is cut out are analyzed in detail to determine the economical and reasonable end reinforcement range.

\section{Project Overview}

The enclosed steel sleeve launching project is located in a water-rich sand layer. The end reinforcement and precipitation are necessary to meet the launching conditions. The outer diameter of the tunnel shield is $6.2 \mathrm{~m}$, and the depth of the tunnel gate is $21.6 \mathrm{~m}$. Due to the dense underground pipelines at the starting end and the limited location of the construction site, it is easy to cause damage to the underground pipelines. Therefore, the design of the three-axis mixing pile reinforcement plan failed to be implemented; instead, it is strengthened by high-pressure rotary jet grouting. Furthermore, before cutting out the tunnel door to install the steel sleeve, we use triple pipe 1850@600 highpressure jet-grouting pile reinforcement (empty pile cement $8 \%$ and solid pile cement $30 \%$ ) outside the station enclosure structure. Simultaneously, three dewatering wells are arranged at the starting end, two dewatering wells are set at $1 \mathrm{~m}$ from the starting end, and one dewatering well is set at the middle of the reinforcement area on the left and right lines. From top to bottom, the beginning soil layer is mainly composed of plain fill, silty clay, organic clay, silty sand, and fine sand. The suggested parameter values of each soil layer are shown in Table 1.

\section{Numerical Model}

Madis GTS, a three-dimensional finite element analysis software, was used to simulate the soil at the end of the triple-tube high-pressure jet-grouting pile. Then, the simulation results of soil displacement and stress after opening the portal was used to study the appropriate reinforcement range. The numerical model is presented in Figure 1. Based on practical experience and Saint-Venant's principle, the area affected by tunnel excavation is basically concentrated within 5 times the tunnel diameter [15-17]. Dimensions of the model used in this study were $100 \mathrm{~m} \times 53 \mathrm{~m} \times 70 \mathrm{~m}$. The Mohr-Coulomb elastoplastic model was adopted for soil, and the shear expansion effect was neglected. The suggested values of the soil parameters are listed in Table 1. The mechanical parameters of cement-soil are related to factors such as the cement mixing ratio, spray pressure, and age. When the unconfined compressive strength of the reinforced soil is $1.0 \mathrm{MPa}$, the cohesion and internal friction angle can be considered as $250 \mathrm{MPa}$ and $25^{\circ}$, respectively [18]. Furthermore, panel units were used for the station enclosure and the tunnel doors. A hybrid grid generator was in the model to obtained the grids, and the number of generated units was 142512, comprising 90601 nodes. To simulate a semiinfinite space, the top of the model is set as a free boundary, then the lower part of the model is set as a fixed boundary, and, finally, the rest of the parts are set with displacement constraints in the normal direction. In the construction phase, the properties of soil elements are altered to simulate the reinforcement afforded by highpressure jet-grouting piles. The procedures involved in construction are as follows: initial ground stress analysis, station foundation excavation and construction of enclosure, high-pressure jet-grouting pile reinforcement, and one-time excavation of tunnel door. To evaluate the influence of the longitudinal reinforcement length on the soil after the excavation of the portal, a lateral reinforcement range of $3 \mathrm{~m}$ is set at the top and bottom of the shield tunnel. Thereafter, the longitudinal reinforcement lengths are set as $3,4,5,6,7$, and $8 \mathrm{~m}$. To study the influence of the lateral reinforcement range on the soil after the excavation of the portal, a longitudinal reinforcement length of $3 \mathrm{~m}$ is fixed behind the portal; then, the lateral reinforcement range is set as 1,2 , and $3 \mathrm{~m}$, respectively.

\section{Analysis of Calculation Results}

4.1. Result Analyses for Different Longitudinal Reinforcement Lengths. Figures 2 and 3 show the displacement and stress under different longitudinal reinforcement lengths. It can be seen from Figure 2 that the three curves of total displacement, X-direction displacement, and Y-direction displacement have the same changing trend. As the length of the reinforced soil increases, the displacement continues to decrease. When the length increases to $5 \mathrm{~m}$, the slope of the curve decreases noticeably; the greater the length of reinforced soil, the smaller is the contribution to the reduction of displacement. When the length of the longitudinal reinforcement increases, the displacement along the Z-direction increases, which is due to the corresponding increase in settlement caused by the increase in the soil weight stress. Figure 3 shows that when the length of reinforced soil increases, the compressive stress of the soil 
TABLE 1: Soil physical and mechanical parameter values.

\begin{tabular}{|c|c|c|c|c|c|c|}
\hline Name of soil layers & $\begin{array}{l}\text { Soil thickness } \\
(\mathrm{m})\end{array}$ & $\begin{array}{l}\text { Elastic modulus } \\
(\mathrm{MPa})\end{array}$ & $\begin{array}{l}\text { Poisson } \\
\text { ratio }\end{array}$ & $\begin{array}{l}\text { Natural gravity }(\mathrm{kN} / \\
\left.\mathrm{m}^{2}\right)\end{array}$ & $\begin{array}{l}\text { Cohesion } \\
\quad(\mathrm{kPa})\end{array}$ & $\begin{array}{c}\text { Internal friction angle } \\
\left({ }^{\circ}\right)\end{array}$ \\
\hline (1) ${ }_{1}$ Plain fill & 1.6 & 16 & 0.20 & 16.0 & 5 & 10 \\
\hline (2) 31 Silty clay & 3.9 & 39 & 0.30 & 15.7 & 12 & 22 \\
\hline (2) ${ }_{32}$ Silty clay & 4.0 & 39 & 0.31 & 15.9 & 11 & 22 \\
\hline (2) ${ }_{21}$ Silty clay & 1.6 & 20 & 0.30 & 15.6 & 23 & 14 \\
\hline (2) ${ }_{33}$ Silty clay & 2.7 & 43 & 0.31 & 15.8 & 11 & 21 \\
\hline (2) ${ }_{22 \mathrm{~F}}$ Organic clay & 6.2 & 15 & 0.33 & 12.4 & 26 & 13 \\
\hline (2) ${ }_{53}$ Fine sand & 10.0 & 25 & 0.30 & 20.0 & 0 & 30 \\
\hline (3) 21 Silty clay & 40.0 & 27 & 0.31 & 16.4 & 24 & 13 \\
\hline
\end{tabular}

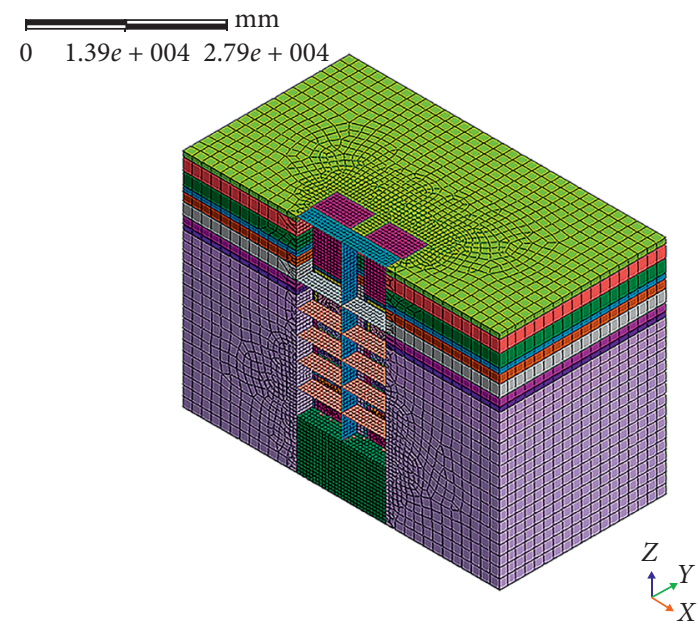

Figure 1: Three-dimensional numerical model.

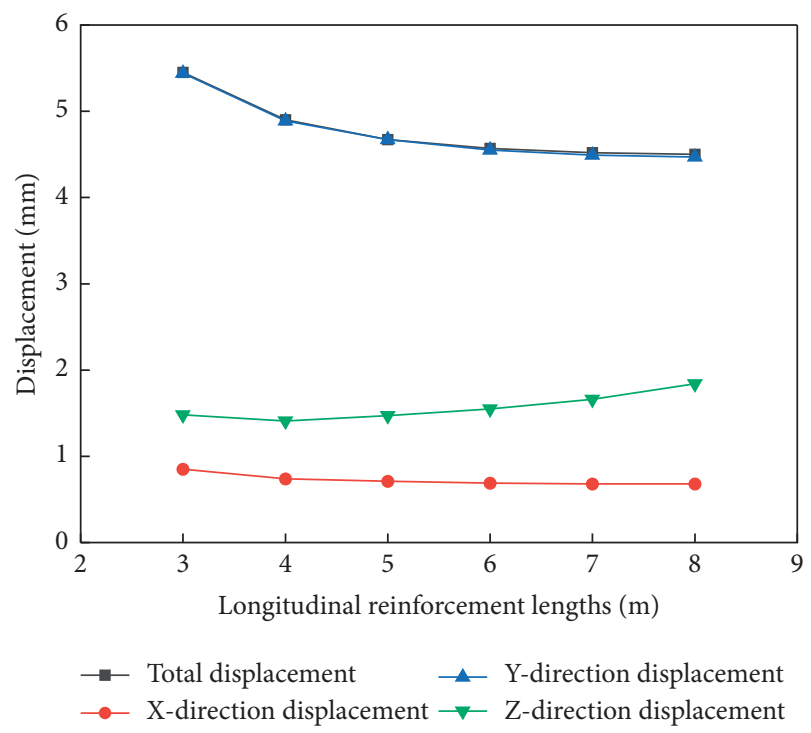

Figure 2: Displacement under longitudinal reinforced lengths of $3 \mathrm{~m}, 4 \mathrm{~m}, 5 \mathrm{~m}, 6 \mathrm{~m}, 7 \mathrm{~m}$, and $8 \mathrm{~m}$.

fluctuates in the range of $0.47 \sim 0.49 \mathrm{MPa}$, the shear stress fluctuates in the range of $0.15 \sim 0.17 \mathrm{MPa}$, and the tensile stress fluctuates in the range of $0.014 \sim 0.017 \mathrm{MPa}$. It can be seen that increasing the length of reinforcement has no significant effect on soil stress.

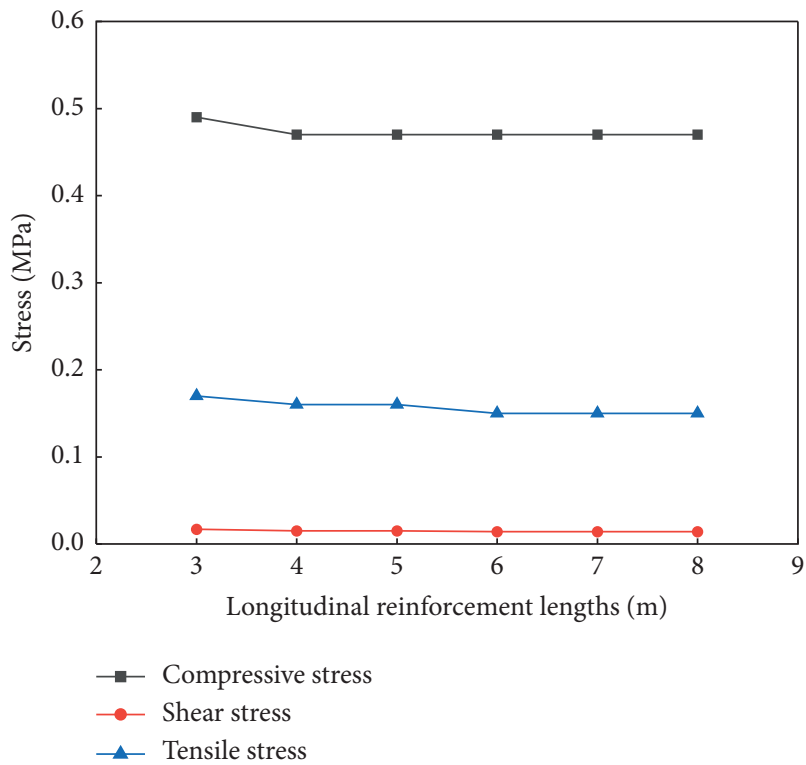

Figure 3: Stresses under longitudinal reinforced lengths of $3 \mathrm{~m}$, $4 \mathrm{~m}, 5 \mathrm{~m}, 6 \mathrm{~m}, 7 \mathrm{~m}$, and $8 \mathrm{~m}$.

In order to determine the feasibility when the longitudinal reinforcement length is $3 \mathrm{~m}$, the soil displacement, stress, and surface settlement are analyzed in detail. Figure 4 depicts a cloud diagram of soil displacement. From Figure 4(a), it can be seen that the maximum displacement along the $\mathrm{X}$-direction is $0.85 \mathrm{~mm}$, which shows that the soil in the middle of the portal is squeezed toward the edges on both sides. It can be seen from Figure 4(b) that the maximum displacement along the $\mathrm{Y}$-direction is $5.44 \mathrm{~mm}$, which occurs at the center of the portal; this shows that the soil behind the door moves toward the exposed surface of the tunnel. According to the technical code for building foundation pit inspection [19], the horizontal displacement control depth of the foundation pit supported by the diaphragm wall is $6.48 \mathrm{~mm}$, when the design depth of the foundation pit is $21.6 \mathrm{~m}$. Hence, the Y-direction displacement meets the safety requirement. As shown in Figure 4(c), the maximum displacement in the Z-direction is $0.67 \mathrm{~mm}$, while the minimum is $-1.48 \mathrm{~mm}$, which shows that the soil above the portal slides downward and the soil below the portal bulges upward. According to the technical specifications for subway construction and inspection [20], when the safety status of the rail transit structure is Class I, the vertical displacement 


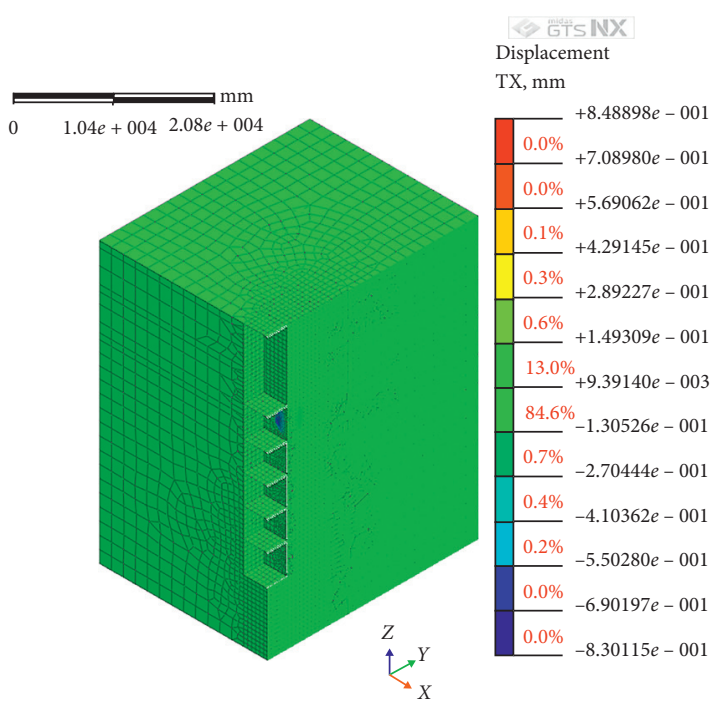

[Data] 1 , cutting out the door, INCR $=1($ load $=1.000)$, [unit $] \mathrm{N}, \mathrm{mm}$

(a)

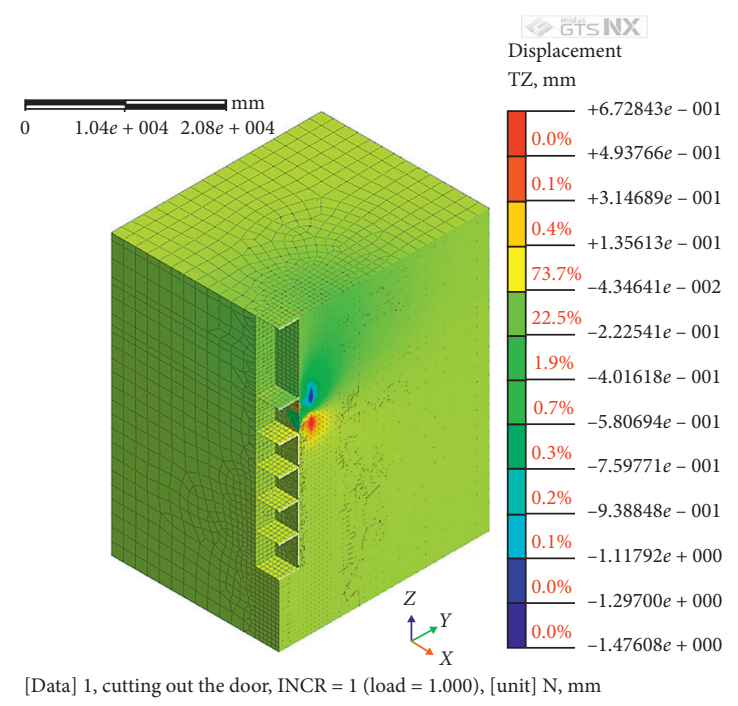

(c)

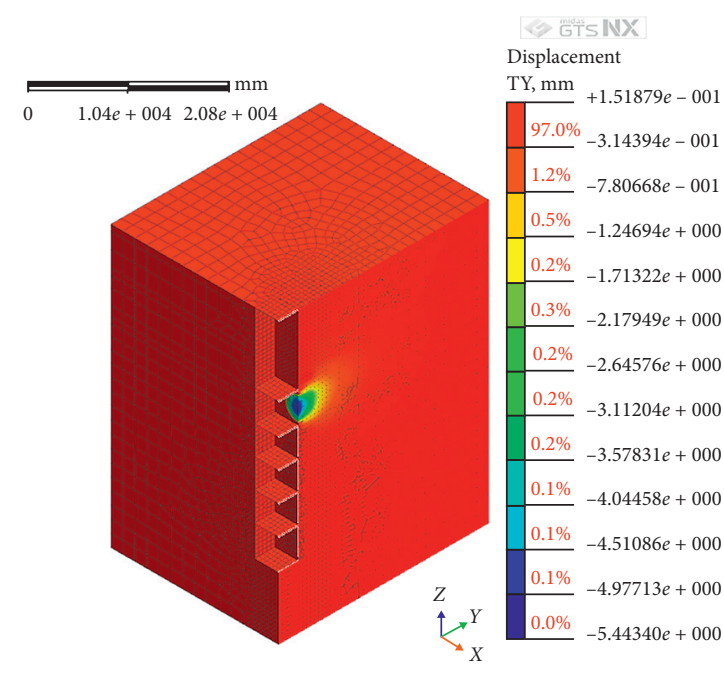

[Data] 1 , cutting out the door, INCR $=1($ load $=1.000)$, [unit $] \mathrm{N}, \mathrm{mm}$

(b)

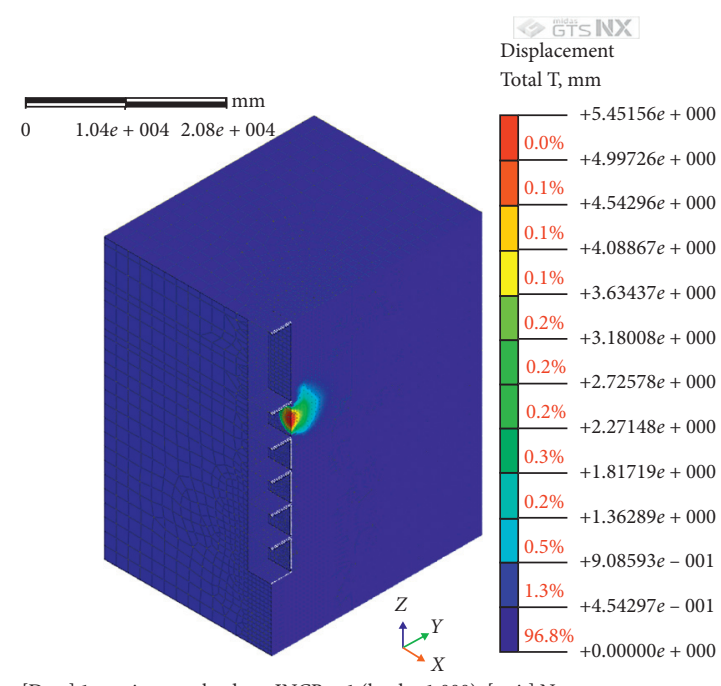

[Data] 1 , cutting out the door, INCR $=1($ load $=1.000)$, [unit] $\mathrm{N}, \mathrm{mm}$

(d)

FIgURE 4: Soil displacement nephogram. (a) X-direction displacement. (b) Y-direction displacement. (c) Z-direction displacement. (d) Total displacement.

safety value of the structural safety control index is $5 \mathrm{~mm}$. Hence, the Z-direction displacement is within the safe limits. From Figure $4(\mathrm{~d})$, it can be seen that the maximum total displacement is $5.45 \mathrm{~mm}$, which appears on the exposed face; this is basically the same as the displacement in the Y-direction. Therefore, soil deformation is mainly composed of the horizontal displacement along the longitudinal direction of the tunnel; the displacements along the other two directions have limit effect on portal stability.

Figure 5 shows the reinforced soil stress. It can be seen from Figure $5(\mathrm{a})$ that the maximum compressive stress, $\sigma_{\mathrm{x}}$, is $0.35 \mathrm{MPa}$, which occurs on both sides of the portal. Figure 5(b) shows that $\sigma_{y}$ involves tensile and compressive stresses; the maximum compressive stress is $0.45 \mathrm{MPa}$, which occurs at the top of the portal, and the maximum tensile stress is $0.017 \mathrm{MPa}$, which occurs at the edges of both sides of the portal. It can be seen from Figure 5(c) that the compressive stress, $\sigma_{z}$, induces delamination, and the maximum compressive stress is $0.48 \mathrm{MPa}$, which occurs at the bottom of the portal. The unconfined compressive strength of the soil reinforced by high-pressure jet-grouting piles for 28 days is generally required to be no less than $0.8 \mathrm{MPa}$. Therefore, the maximum compressive stress in the reinforced soil caused by the removal of the portal is less than its compressive strength. According to the Griffith strength criterion, the compressive strength is 8 times the tensile strength, that is, $\sigma_{c}=8 \sigma_{t}$, and the tensile strength of the reinforced soil is $0.1 \mathrm{MPa}$. Hence, the maximum tensile stress is considerably smaller than its tensile strength. From Figures 5(d) and 5(e), it can be seen that the maximum shear stress is $0.17 \mathrm{MPa}$, which appears on both sides of the portal. Based on the Coulomb formula, that is, 


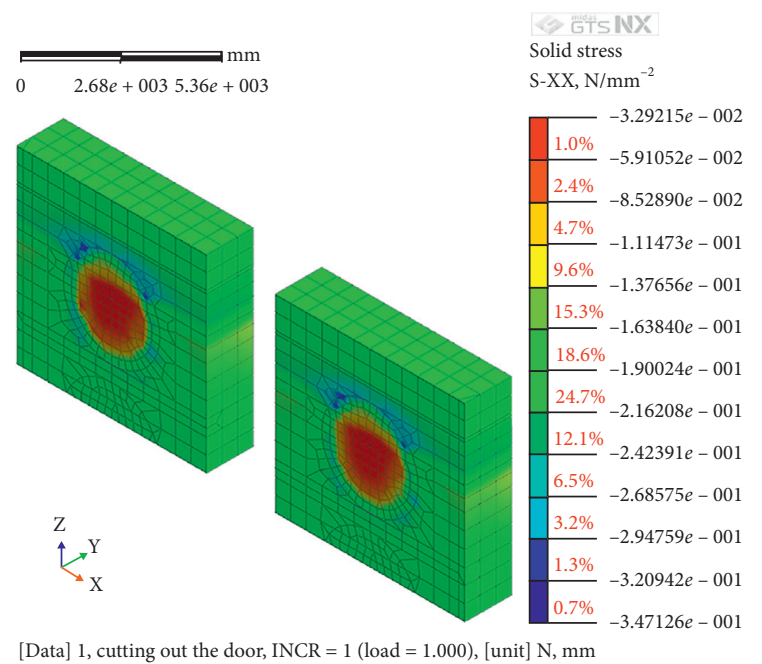

(a)

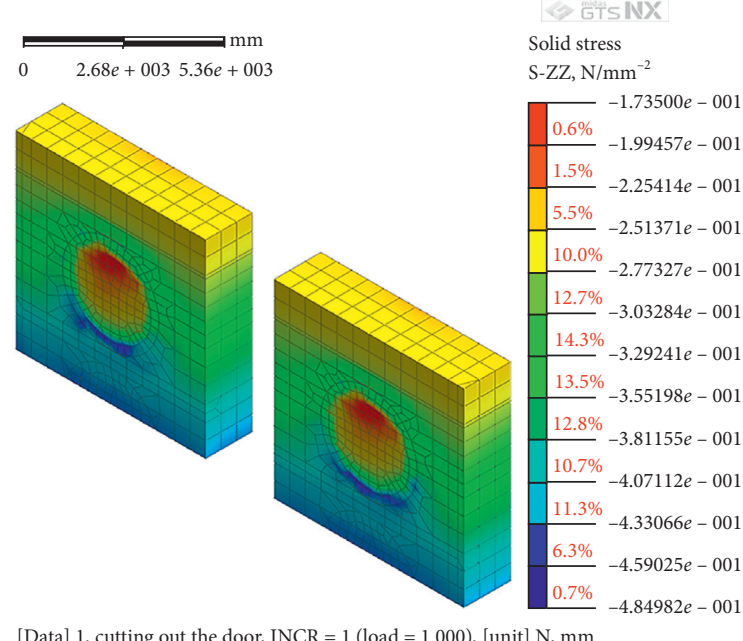

(c)

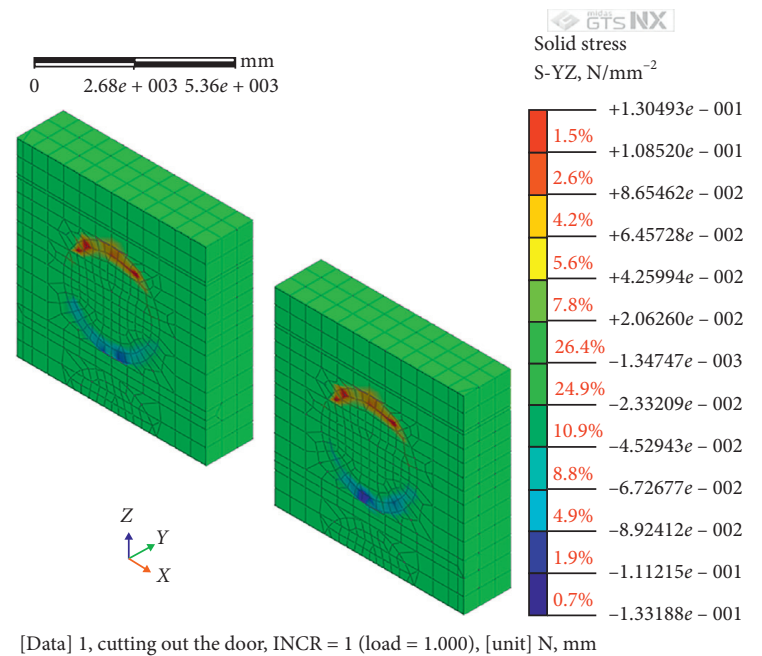

(e)

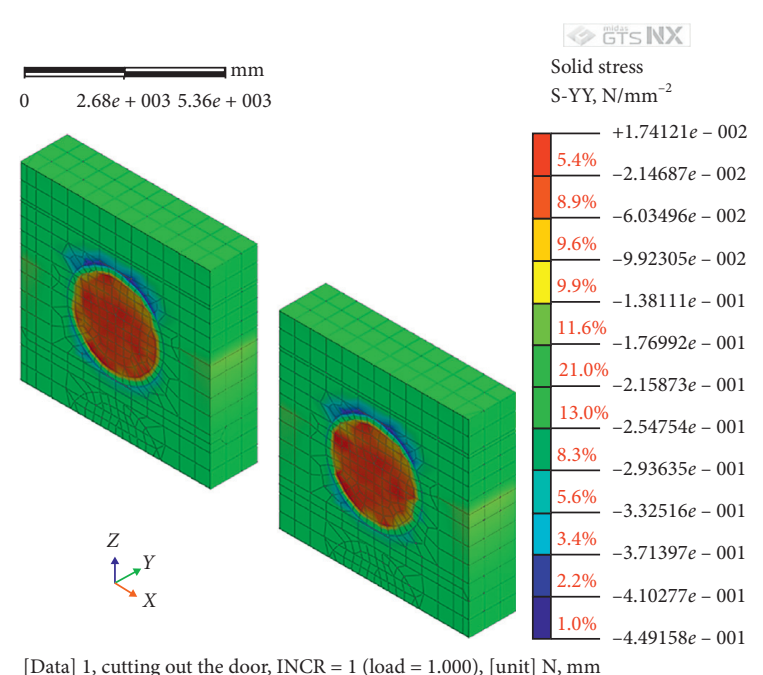

(b)

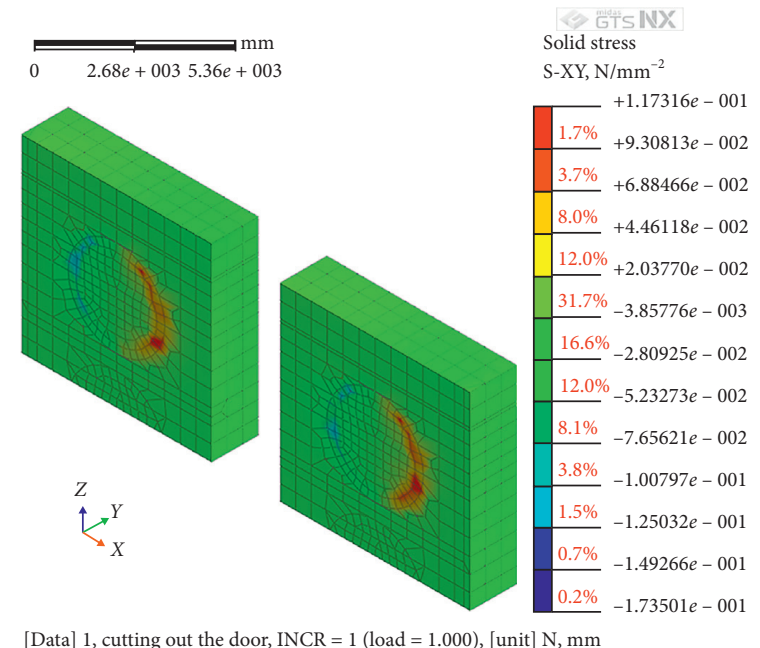

(d)

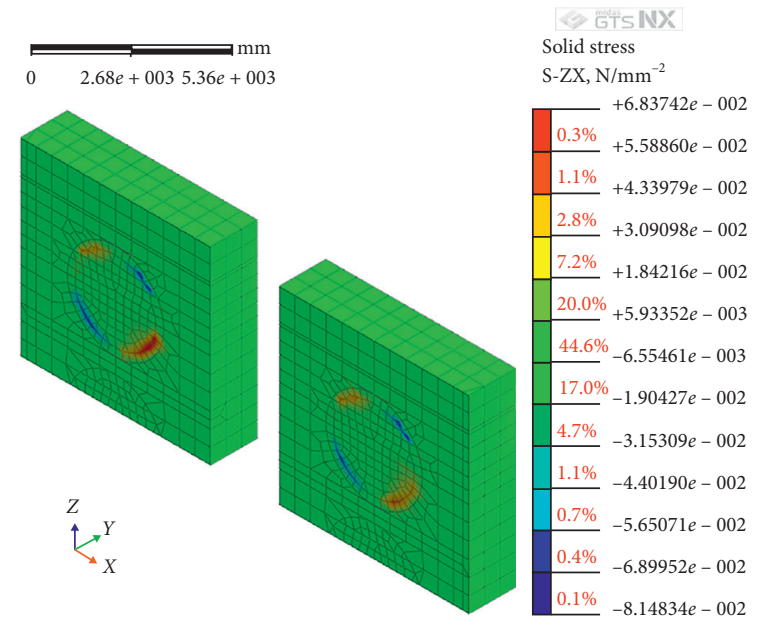

[Data] 1 , cutting out the door, INCR $=1($ load $=1.000)$, [unit] N, mm

(f)

FIGURE 5: Stresses of reinforcement soil. (a) Stress of $\sigma_{x}$. (b) Stress of $\sigma_{y}$. (c) Stress of $\sigma_{z}$. (d) Stress of $\tau_{x y}$. (e) Stress of $\tau_{y z}$. (f) Stress of $\tau_{x z}$. 


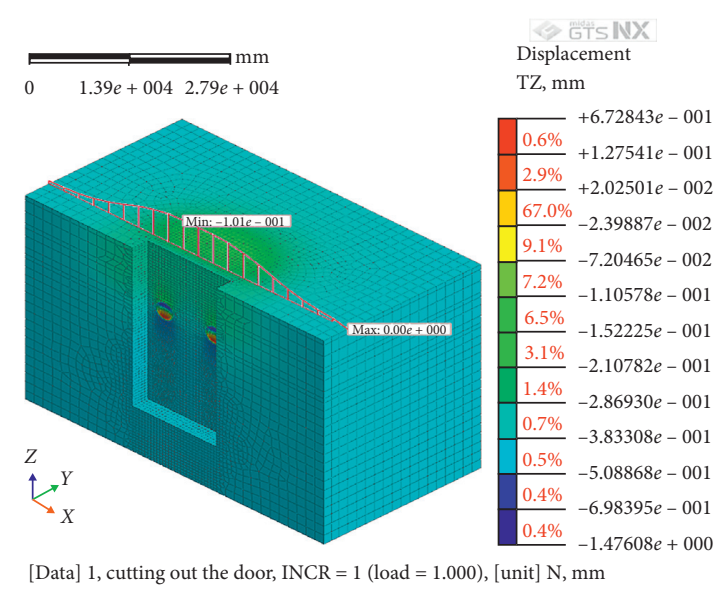

FIGURE 6: Surface subsidence diagram at $3 \mathrm{~m}$ of longitudinal reinforcement length.

$\tau_{f}=\sigma \tan \phi+c$, the shear strength of the reinforced soil is $0.31 \mathrm{MPa}$. Therefore, the maximum shear stress of the reinforced soil caused by the removal of the tunnel door is less than its shear strength.

Figure 6 shows the surface settlement. It can be seen from Figure 6 that the surface settlement trough caused by the simultaneous removal of the left and right portals has a "V" shape, which is approximately a normal distribution curve, and the maximum settlement is less than $1 \mathrm{~mm}$, which appears on the central axis of the two portals. According to the technical specifications for subway construction and inspection [20], the vertical displacement safety value of the structure is $5 \mathrm{~mm}$; therefore, the surface settlement meets the safety requirements.

4.2. Result Analysis of Different Lateral Reinforcement Ranges. Figures 7 and 8 show the displacement and stress under different lateral reinforcement ranges. It can be seen from the figures that, with the reduction in the lateral reinforcement range, the soil displacement and stress do not change, which indicates that the effective reinforcement range of high-pressure jet-grouting piles is limited. The strength and stability of soil are not affected by changing the transverse reinforcement scope.

To further study the feasibility when the lateral reinforcement range is $1 \mathrm{~m}$, the soil displacement, stress, and ground settlement are analyzed in detail. Figure 9 shows a cloud diagram of soil displacement. It can be seen from Figure 9(a) that the maximum displacement in the X-direction is $0.89 \mathrm{~mm}$, which appears on both sides of the portal. It can be seen from Figure 9(b) that the maximum displacement in the Y-direction is $5.51 \mathrm{~mm}$, and the deformation area and displacement are unchanged. It can be seen from Figure 9(c) that the maximum displacement in the $\mathrm{Z}$-direction is $1.50 \mathrm{~mm}$, and the settlement range has been significantly expanded but the value has not changed. It can be seen from Figure 9(d) that the maximum total displacement is $5.52 \mathrm{~mm}$, with only a small increase of $0.07 \mathrm{~mm}$. Generally, although the reduction in the lateral reinforcement range increases the soil settlement area, the displacement remains unchanged.

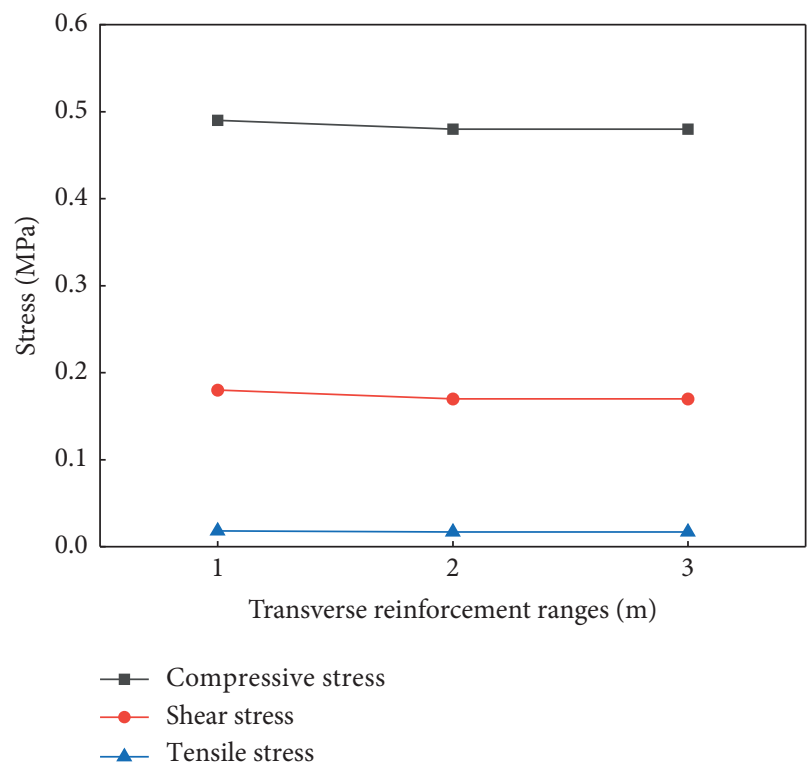

Figure 7: Stresses under transverse reinforcing ranges of $1 \mathrm{~m}, 2 \mathrm{~m}$, and $3 \mathrm{~m}$.

Figure 10 shows the reinforced soil stress. It can be seen from Figure 10(a) that the maximum compressive stress of $\sigma_{x}$ is $0.35 \mathrm{MPa}$, which shows that the soil in the middle of the portal is squeezed to the edges on both sides. It can be seen from Figure 10(b) that the maximum compressive stress of $\sigma_{y}$ is $0.47 \mathrm{MPa}$, which appears on top of the portal, and the maximum tensile stress of $\sigma_{y}$ is $0.017 \mathrm{MPa}$, which appears at the edges of both sides of the portal. From Figure 10(c), it can be seen that the maximum compressive stress of $\sigma_{z}$ is $0.49 \mathrm{MPa}$, with a small increase of $0.01 \mathrm{MPa}$. From Figures $10(\mathrm{~d})$ and $10(\mathrm{e})$, it can be seen that the maximum shear stress is $0.18 \mathrm{MPa}$, which remains unchanged. In general, the various stresses of the reinforced soil meet the strength requirements.

Figure 11 shows the surface settlement. It can be seen from Figure 11 that although the reduction in the lateral reinforcement range leads to an increase in the settlement area, the maximum settlement is still less than 


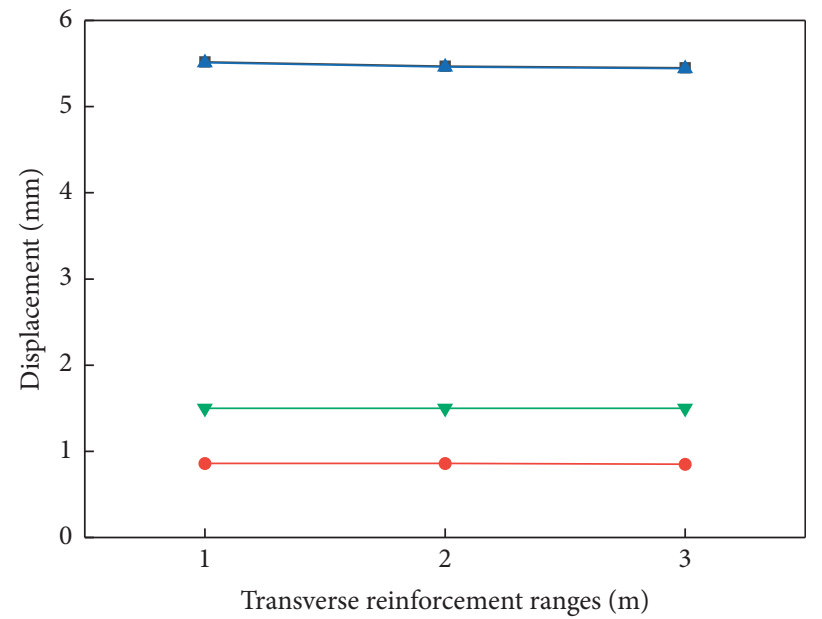

$\rightarrow$ Total displacement $\rightarrow$ Y-direction displacement
$\rightarrow$ X-direction displacement $\rightarrow$ Z-direction displacement

FIgURE 8: Displacement under transverse reinforcing ranges of $1 \mathrm{~m}, 2 \mathrm{~m}$, and $3 \mathrm{~m}$.

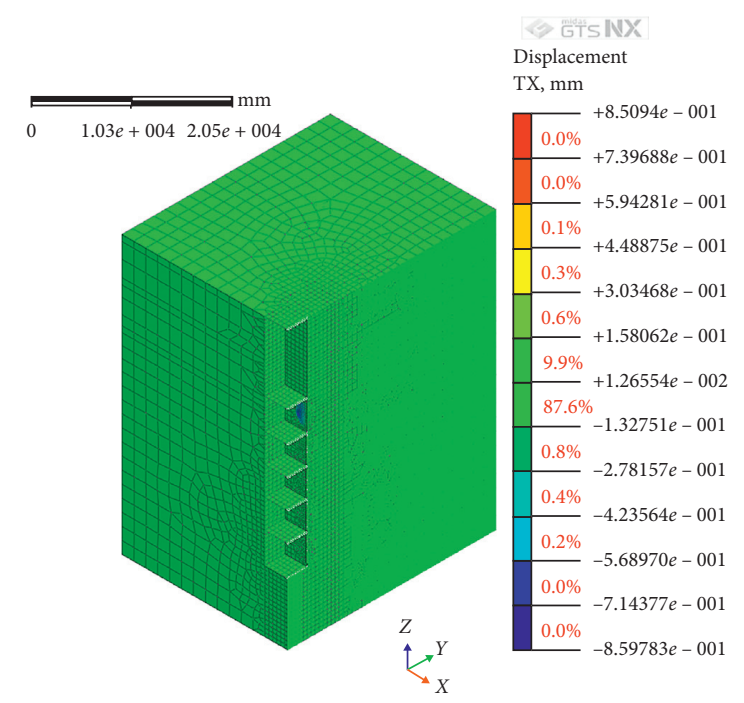

[Data] 1 , cutting out the door, INCR $=1($ load $=1.000)$, [unit $] \mathrm{N}, \mathrm{mm}$

(a)

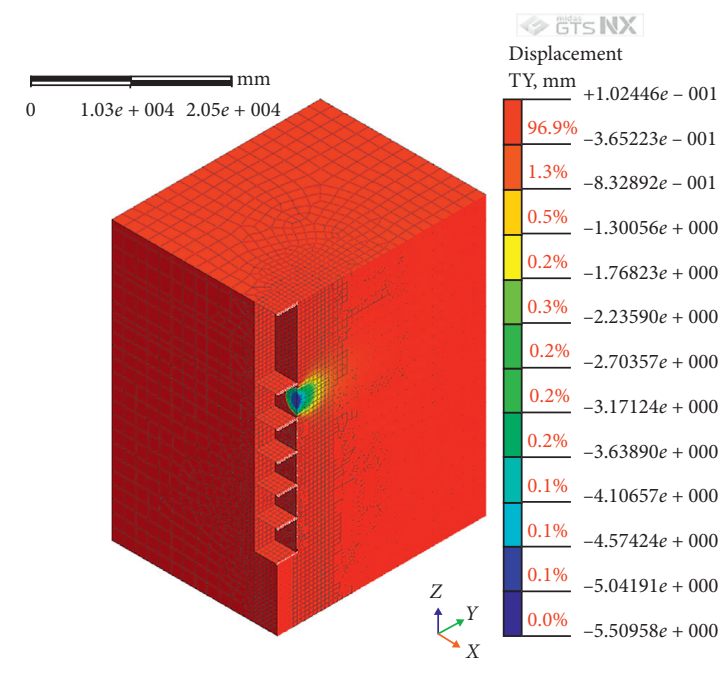

[Data] 1 , cutting out the door, $\mathrm{INCR}=1(\mathrm{load}=1.000)$, [unit $] \mathrm{N}, \mathrm{mm}$

(b)

FIgure 9: Continued. 


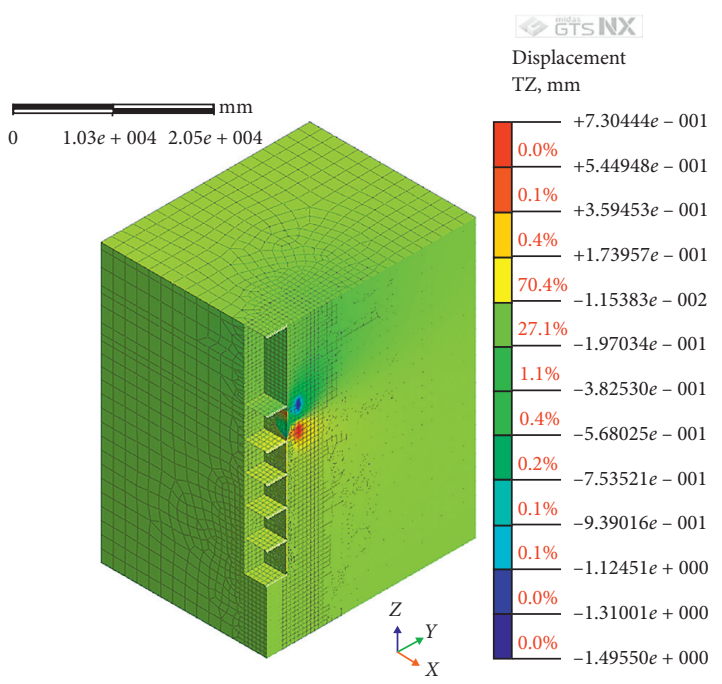

[Data] 1 , cutting out the door, INCR $=1($ load $=1.000)$, [unit $] \mathrm{N}, \mathrm{mm}$

(c)

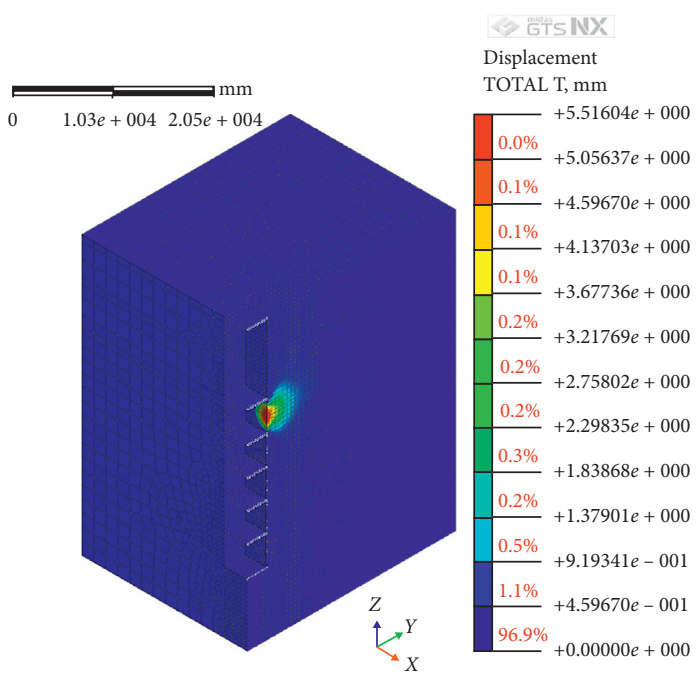

[Data] 1 , cutting out the door, INCR $=1($ load $=1.000)$, [unit] $\mathrm{N}, \mathrm{mm}$

(d)

Figure 9: Soil displacement nephogram. (a) X-direction displacement. (b) Y-direction displacement. (c) Z-direction displacement. (d) Total displacement.

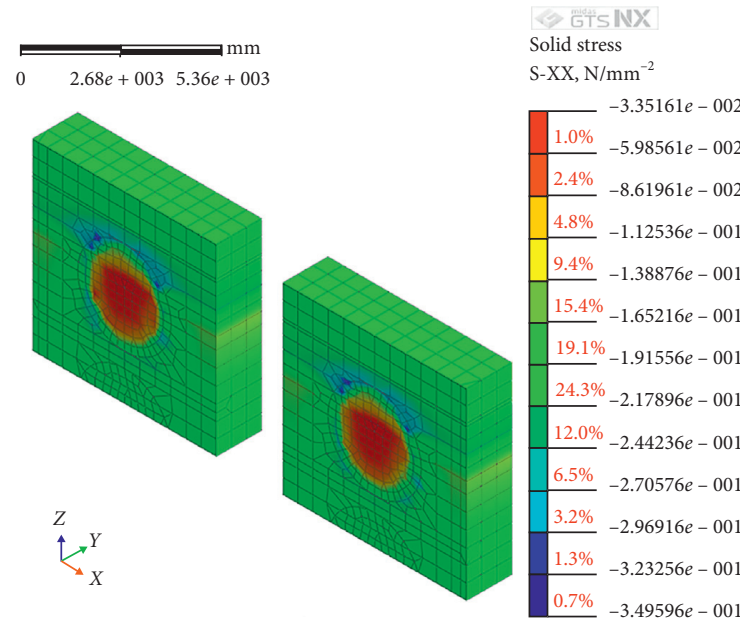

[Data] 1 , cutting out the door, $\mathrm{INCR}=1($ load $=1.000)$, [unit $] \mathrm{N}, \mathrm{mm}$

(a)

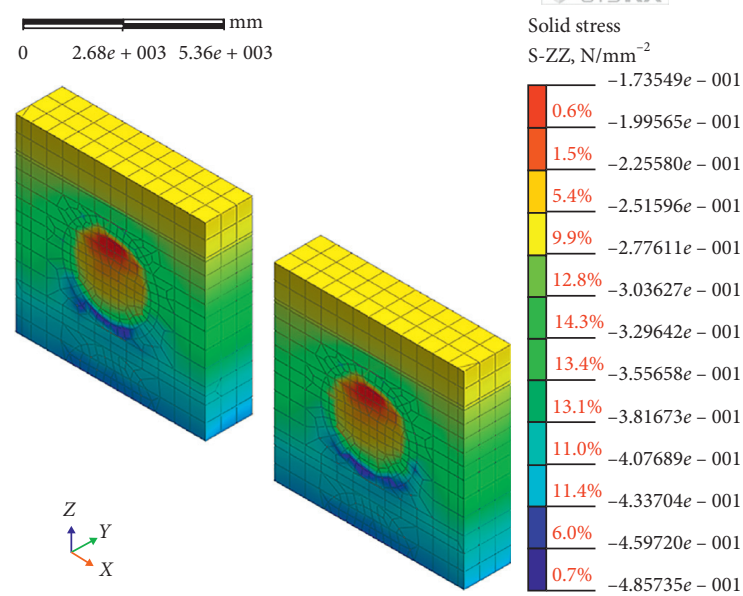

[Data] 1 , cutting out the door, $\mathrm{INCR}=1($ load $=1.000)$, [unit $] \mathrm{N}, \mathrm{mm}$

(c)

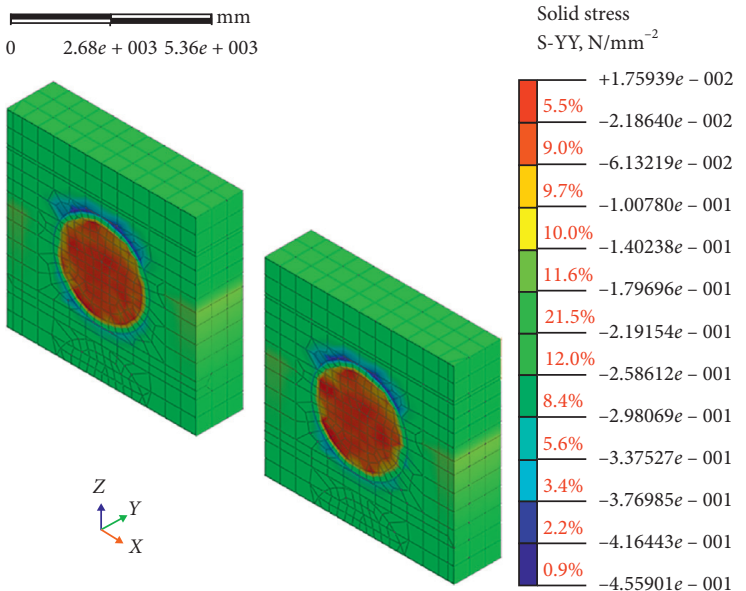

[Data] 1 , cutting out the door, INCR $=1($ load $=1.000)$, [unit $] \mathrm{N}, \mathrm{mm}$

(b)

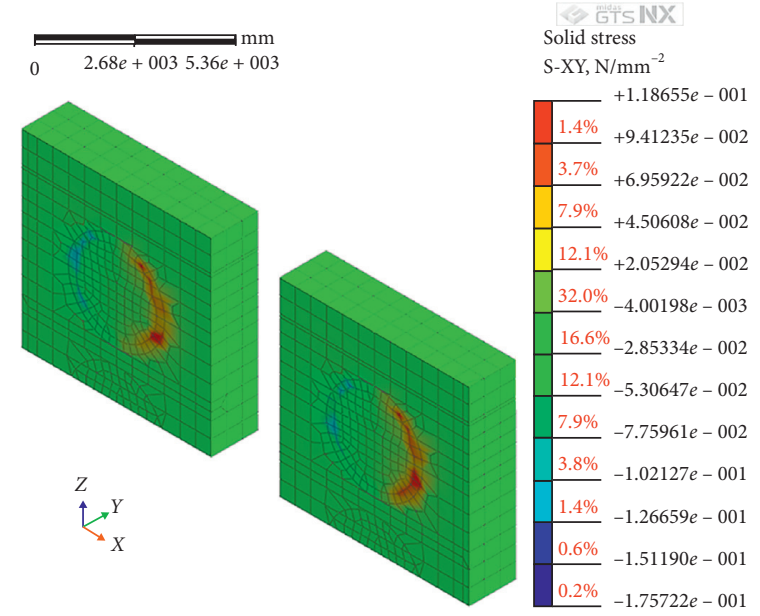

[Data] 1 , cutting out the door, INCR $=1($ load $=1.000)$, [unit $] \mathrm{N}, \mathrm{mm}$

(d)

FIgURE 10: Continued. 


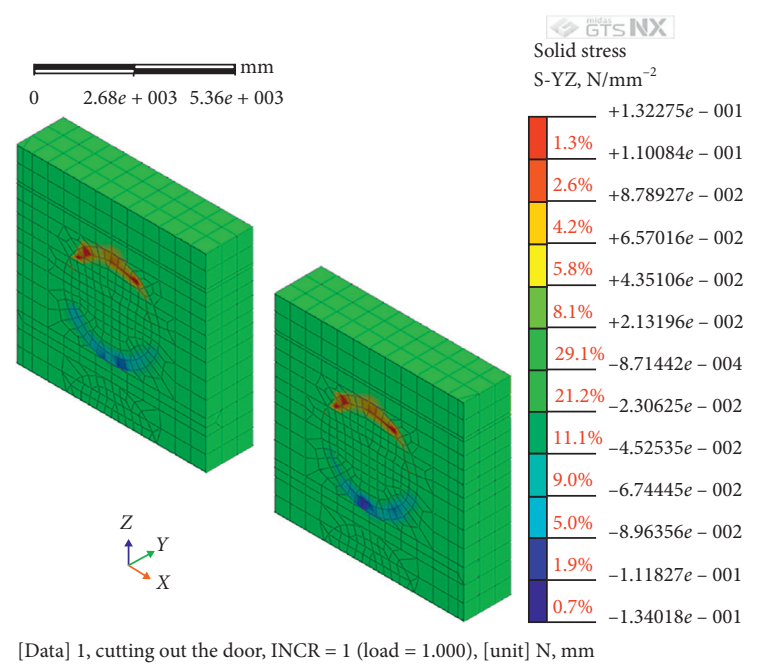

(e)

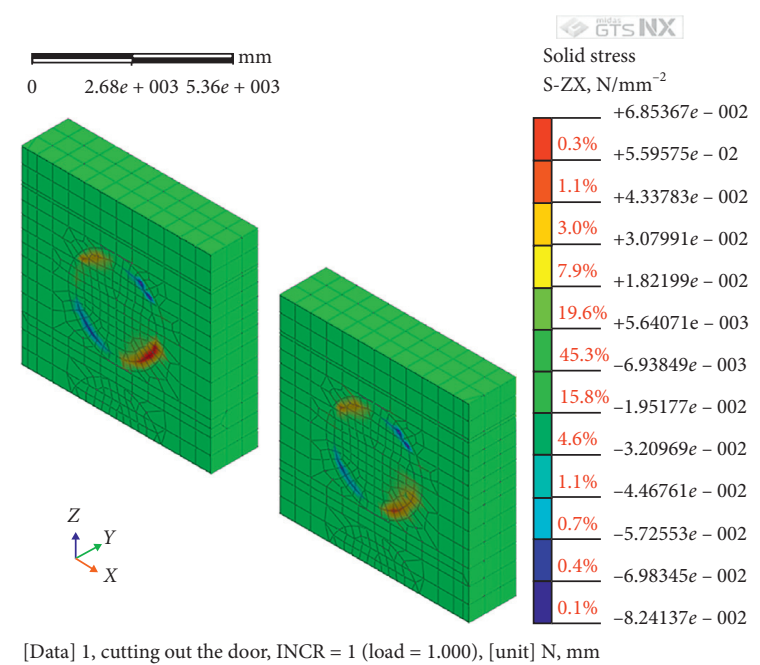

(f)

FIGURE 10: Stresses of reinforcement soil. (a) Stress of $\sigma_{x}$. (b) Stress of $\sigma_{y}$. (c) Stress of $\sigma_{z}$. (d) Stress of $\tau_{x y}$. (e) Stress of $\tau_{y z}$. (f) Stress of $\tau_{x z}$.

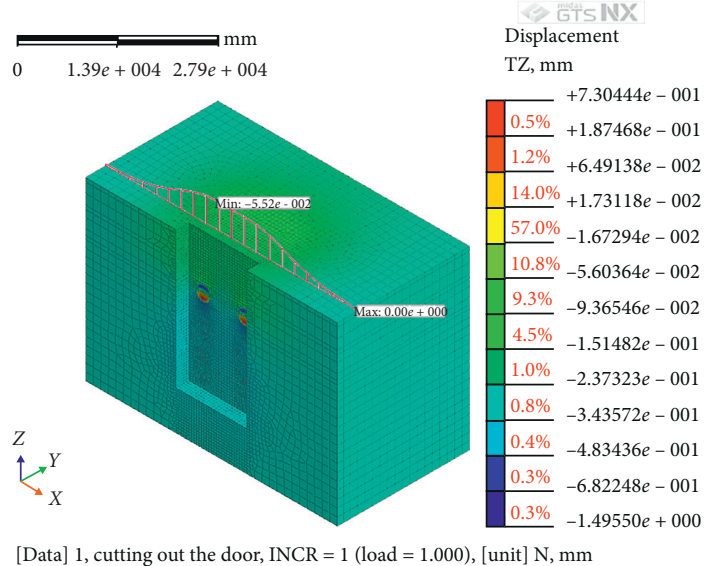

Figure 11: Surface subsidence diagram at $1 \mathrm{~m}$ of lateral reinforcement.

$1 \mathrm{~mm}$, which meets the requirements of rail transit regulations.

\section{Conclusions and Discussion}

Based on a sealed steel sleeve launching project, this study uses Madis GTS to simulate the triple-tube high-pressure jetgrouting pile to reinforce the water-rich sand layer. The changes in soil displacement and stress at different longitudinal reinforcement lengths and lateral reinforcement ranges were studied in detail. The following conclusions are drawn from the study:

(1) The overall displacement of the soil tends to decrease with an increase in the length of the longitudinal reinforcement, and the greater the length of the reinforced soil, the smaller the reduction in displacement. With the decrease in the lateral reinforcement range, the soil settlement area increases; however, the displacement remains unchanged.
(2) Irrespective of whether the reinforcement length or the transverse reinforcement scope changes, the soil stress remains unchanged after the hole door is removed.

(3) The soil deformation is mainly composed of horizontal displacement along the longitudinal direction of the tunnel; the displacement in other directions has little effect on portal stability. The compressive stress $\sigma_{z}$ is the largest among the various stresses of the soil, and the tensile stress and shear stress are generally small.

(4) When the reinforcement range is reduced, although the settlement area increases, the maximum surface settlement is still less than $1 \mathrm{~mm}$, appearing between the central axis of the left and right portals.

Based on the strength and stability of the soil, the longitudinal reinforcement length and the lateral reinforcement range of the end can be taken as $3 \mathrm{~m}$ and $1 \mathrm{~m}$, respectively, which is greatly reduced compared to the traditional reinforcement range. However, if the construction control of high-pressure jet-grouting piles does not meet the requirements, it is difficult to guarantee the effect of preventing the cave door from collapsing. Common construction quality defects include broken piles, necking piles, clogging nozzle, and pile head cavities. When the borehole slope deviation is large, the antiseepage effect of the waterstop curtain composed of piles is not good. Therefore, the design of the end reinforcement range should be appropriately designed based on the actual construction situation. On the other hand, the scope of application of high-pressure jet-grouting piles is limited. For example, if the groundwater flow rate is too high in a water-rich sand layer, the sprayed grout will not be able to solidify around the grouting pipe. The reinforcement method of plain underground continuous wall suitable for this complex condition needs further study. 


\section{Data Availability}

The data used to support the findings of this study are available from the corresponding author upon request.

\section{Conflicts of Interest}

The author declares no conflicts of interest.

\section{Acknowledgments}

The author wishes to thank China Construction Communications Construction Group Co. Ltd. for offering field data. This study was funded by the Promotion Program (Grant No. ZQN-PY513).

\section{References}

[1] W. L. Wu, H. H. Zhu, Y. Zhou et al., "Study of key technologies of steel sleeve launching and receiving of shield," Chinese Journal of Tunnel Construction, vol. 37, pp. 872-877, 2017.

[2] S. S. Lv, W. Liu, S. H. Zhai et al., "Influence of water inrush from excavation surface on the stress and deformation of tunnel-forming structure at the launching-arrival stage of subway shield," Advances in Civil Engineering, vol. 2019, p. 20, Article ID 6989730, 2019.

[3] X. Chen, M. Fang, P. Chen, Q. Cai, and L. Guo, "Effects of ultrasonic stimulation on the transport of different-sized particles in porous media," Hydrogeology Journal, vol. 28, no. 4, pp. 1403-1417, 2020.

[4] B. Bai, D. Y. Rao, T. Chang et al., "A nonlinear attachmentdetachment model with adsorption hysteresis for suspensioncolloidal transport in porous media," Journal of Hydrology, vol. 578, Article ID 124080, 2019.

[5] W. Li, X. Fan, F. Huang et al., "Uncertainties analysis of collapse susceptibility prediction based on remote sensing and GIS: influences of different data-based models and connections between collapses and environmental factors," Remote Sensing, vol. 12, no. 24, p. 4134, 2020.

[6] X. L. Nguyen, L. Wu, and K. T. Nguyen, "Application research of high pressure jet grouting pile in an underground engineering in Vietnam," Archives of Civil Engineering, vol. 66, pp. 575-593, 2020.

[7] X. Chen, Z. Wu, Q. Cai, and W. Cao, "Effect of ultrasonic stimulation on particle transport and fate over different lengths of porous media," Journal of Hydrology, vol. 559, pp. 972-983, 2018.

[8] J. Hu, H. Zeng, and X. B. Wang, "Numerical analysis of temperature field of cup-shaped frozen soil wall reinforcement at shield shaft," Applied Mechanics and Materials, vol. 341-342, pp. 1467-1471, 2013.

[9] J. Hu and P. Yang, "A numerical simulation study on the chemical reinforcement area at shield start shaft," in Proceedings of the International Conference on Electric Technology and Civil Engineering (ICETCE), Lushan, China, April 2011.

[10] X. J. Zhou, J. H. Wang, X. B. Wang et al., "Study on launching and receiving technology of shield tunnel," in Proceedings of the International Conference on Pipelines and Trenchless Technology 2011: Sustainable Solutions for Water, Sewer, Gas, and Oil Pipelines, Beijing, China, October 2011.

[11] Y. W. Wu, Analysis of the Ground Settlement Caused by the Construction of the Portal of the Shield Starting Shaft in the
East Huai'an Station. Master, Anhui Jianzhu University, Hefei, China, 2020.

[12] F. R. Luo, Y. S. Jiang, and H. Jiang, "Theoretical modeling and sensitivity analysis of improved sandy strata at TBM portal areas with strength and stability theories," Chinese Journal of Engineering Geology, vol. 19, pp. 364-369, 2011.

[13] J. S. Lei, L. M. Yin, X. Z. Yang et al., "Study on reinforcement scope at TBM launching and breaking through area in sandy pebble stratum," in Proceedings of the International Conference on Pipelines \& Trenchless Technology, Xi'an, China, October 2013.

[14] Y. S. Jiang and H. Jian, "Study on soil reinforcement for the launching and arrival ends of large-diameter EPB shields in Beijing metro," Chinese Journal of Urban Rapid Rail Transit, vol. 26, pp. 93-96, 2013.

[15] L. Zhu, L. Huang, L. Fan et al., "Landslide susceptibility prediction modeling based on remote sensing and a novel deep learning algorithm of a cascade-parallel recurrent neural network," Sensors, vol. 20, no. 6, p. 1576, 2020.

[16] J. Lai, H. Zhou, K. Wang et al., "Shield-driven induced ground surface and Ming Dynasty city wall settlement of Xi'an metro," Tunnelling and Underground Space Technology, vol. 97, Article ID 103220, 2020.

[17] F. Huang, Z. Cao, S.-H. Jiang, C. Zhou, J. Huang, and Z. Guo, "Landslide susceptibility prediction based on a semi-supervised multiple-layer perceptron model," Landslides, vol. 17, no. 12, pp. 2919-2930, 2020.

[18] K. H. Gu and Y. F. Zhang, "Parametric study on soil reinforcement in front of lattice shaped diaphragm wall revetment on soft ground," Chinese Journal of Port \& Waterway Engineering, vol. 4, pp. 134-139, 2018.

[19] Ministry of Housing and Urban-Rural Development of the People's Republic of China, State Administration for Market Regulation, China Planning Press, Beijing, China, 2019.

[20] Ministry of Housing and Urban-Rural Development of the People's Republic of China, General Administration of Quality Supervision, Inspection and Quarantine of the People's Republic of China, China Building Industry Press, Beijing, China, 2017. 